\title{
Evolução das mídias populares no Brasil (1980-2015): avanços, desafios e perspectivas*
}

\author{
The evolution of popular media in Brazil (1980-2015): advances, \\ challenges and perspectives
}

\begin{abstract}
Ana Suzina ${ }^{1}$
Resumo: Esta comunicação discute as condições atuais para o desenvolvimento de mídias populares no Brasil, a partir dos resultados de uma pesquisa doutoral realizada entre $2013 \mathrm{e}$ 2018, junto a 29 experiências em seis regiões do país. O artigo explora as evoluções nesse campo em relação às condições estruturais, com especial atenção ao acesso e ao uso de tecnologias digitais, em comparação com a situação descrita por Cicilia Peruzzo para os anos 1980-90. O acesso a recursos financeiros continua sendo um dos principais desafios. Embora as estratégias de comunicação tenham maior relevância nas ações de mudança social e a ruptura digital represente oportunidades para desenvolver modelos alternativos de financiamento, as fontes financeiras ainda são frágeis e instáveis. $\mathrm{O}$ acesso a equipamentos e o perfil das equipes apresentam, por sua vez, notáveis transformações. A evolução tecnológica em geral e os requisitos de regularização, no caso particular dos audiovisuais, renovaram as práticas.
\end{abstract}

Palavras-Chave: mídias populares, tecnologias digitais, história, Brasil.

\begin{abstract}
This paper discusses the current conditions for the development of popular media in Brazil, based on the results of a doctoral research conducted between 2013 and 2018, along with 29 experiences in six regions of the country. The article explores developments in this field in relation to structural conditions, with special attention to access and use of digital technologies, compared to the situation described by Cicilia Peruzzo for the years 1980-90. Access to financial resources continues to be a major challenge. Although communication strategies are more relevant in social change actions and digital divide represents opportunities to develop alternative financing models, financial sources are still fragile and unstable. The access to equipment and the profile of the teams present, in turn, remarkable transformations. The technological evolution in general and the requirements of regularization, in the particular case of audiovisuals, renewed the practices.
\end{abstract}

Keywords: popular media, digital technologies, history, Brazil.

\footnotetext{
*Revisor: Pedro Henrique Tenório. Pesquisa realizada com bolsa da Capes, Ministério da Educação.

${ }^{1}$ Université catholique de Louvain
} 


\section{Introdução}

Este artigo apresenta parte dos resultados de uma pesquisa de doutorado, realizada entre 2013 e 2018, na Universidade Católica de Lovaina, na Bélgica. O estudo envolveu a observação de 29 experiências de mídias populares em seis estados brasileiros, como apresentado mais detalhadamente na próxima seção. A presente reflexão se concentra na análise da evolução de práticas desse gênero no Brasil e se alinha à tradição latinoamericana de estudos de comunicação popular, desenvolvida por estudiosos como Cicilia Peruzzo (Brasil), Mario Kaplun (Uruguai), Jorge Gonzalez (México), entre outros.

O termo "popular" refere-se à cultura das chamadas classes populares na América Latina - que inclui indígenas, moradores de periferias, camponeses e todos os grupos que são frequentemente excluídos da cultura dominante. Fala-se de 'comunicação popular' para discutir o uso geral de processos de comunicação - incluindo não só mídias, mas também quaisquer ferramentas de comunicação como teatro, música, comunicação interpessoal etc. - para empoderar os cidadãos, dentro de um contexto histórico e socioeconômico, por meio da participação. Mais especificamente, fala-se de 'mídia popular' para discutir a apropriação de meios de comunicação por esses grupos, com o objetivo de produzir ou destacar uma narrativa oposta a outra dominante (GONZÁLEZ, 1990; PERUZZO, 2008). A ideia de 'mídia popular' se refere também a práticas que buscam a emancipação e a melhoria das condições de vida desses grupos (GIMENEZ, 1984; FESTA, 1984; OTRE, 2016). O desenvolvimento do conceito, diretamente ligado às experiências concretas e à reflexividade no campo de ação, é fortemente influenciado pelo trabalho do educador brasileiro Paulo Freire, que promove a compreensão da comunicação como uma “coparticipação dos sujeitos nos processos de aquisição de conhecimento" (COGO, 2009).

A corrente latino-americana da comunicação popular dialoga fluidamente com a corrente internacional de "Comunicação para a Mudança Social", com acadêmicos de referência como Thomas Tufte (Dinamarca/Reino Unido), Alfonso Gumucio-Dagron (Bolívia), entre outros. Em uma sociedade midiatizada e em rede, como os casos observados demonstram, essas correntes teóricas sugerem que a mudança social exige mais que desenvolvimentos tecnológicos. Elas destacam o espírito de comunidade e a abordagem horizontal como forma de dialogar e reconhecer o valor de cada ser humano e de cada 
experiência como parte de um compromisso com a emancipação de cada indivíduo e da coletividade.

Para entender a evolução das práticas de mídias populares no Brasil, foi importante traçar uma linha do tempo, observando as transformações gerais ocorridas no campo. Este exercício tomou como ponto de partida o estudo referencial de Cicilia Peruzzo (1998) sobre as práticas de comunicação em movimentos sociais no Brasil e na América Latina. Em seu estudo, a autora buscou compreender como ocorria a participação na comunicação popular, mais especificamente na comunicação radiofônica, em experiências realizadas no Brasil e em outros países latino-americanos (PERUZZO, 1998, p. 21). Seu intuito era compreender aspectos da participação popular nas práticas de comunicação que emergiram com intensidade, principalmente a partir da fase de declínio do regime militar brasileiro, a partir do final dos anos 1970.

As descobertas de Peruzzo retratam essas práticas como: (1) constituindo uma grande variedade de produções coletivas em formatos impressos e audiovisuais; (2) baseando-se principalmente nas tecnologias mais baratas e mais rudimentares, embora houvesse algumas experiências mais bem estruturadas, como estações comunitárias de rádio e televisão legalmente implementadas; (3) estar principalmente relacionadas à socialização da informação, ao desenvolvimento da conscientização, à mobilização e organização de ações na busca de soluções para problemas comuns; e (4) carentes de acesso a tecnologias já disponíveis na maioria dos países (PERUZZO, 1998, p. 148-149).

A presente pesquisa mostrou que a maioria dessas características se mantém, apesar de algumas modificações, mais de 30 anos depois. A variedade de produções foi confirmada pela grande diversidade de plataformas tecnológicas utilizadas, que foi ampliada pela incorporação de recursos digitais. Uma das descobertas é exatamente a prevalência de plataformas analógicas em meio à crescente presença de plataformas digitais, revelando diferentes níveis e estratégias de apropriação de tecnologias, além da presença da cultura digital como prática e como horizonte nessas experiências ${ }^{1}$. No presente artigo, concentro-me na evolução da característica (2), discutindo as questões

\footnotetext{
${ }^{1}$ Eu publiquei um artigo explorando aspectos do uso combinado de plataformas analógicas e digitais em mídias populares na revista Commons, em 2018 (ver Suzina, 2018).
} 
estruturais da criação e do desenvolvimento de mídias populares, particularmente no que se refere à incorporação de recursos tecnológicos.

Depois de esboçar, brevemente, os casos e as opções metodológicas da pesquisa, o artigo apresenta uma reflexão crítica sobre a qualificação que se faz das tecnologias utilizadas no campo da comunicação popular e, em seguida, se divide em três seções que exploram as evoluções das mídias populares em formato impresso, de televisão e de rádio, incluindo um estudo de caso para cada uma das plataformas audiovisuais. A discussão se conclui com uma breve seção de considerações finais.

\section{Casos observados e metodologia}

Este artigo apresenta parte dos resultados de um trabalho de campo de múltiplos casos (HANNERZ, 2003), fundamentado em entrevistas com 55 comunicadores e observação de 29 iniciativas de mídia popular vinculadas a 17 grupos - movimentos sociais, ONGs e associações comunitárias - situadas em seis estados do país: Paraná, São Paulo, Minas Gerais, Rio Grande do Norte, Ceará e Pará. A lista completa de estudos de caso, observados de novembro de 2013 a junho de 2016, está indicada na Tabela 1. A abordagem com múltiplos casos foi escolhida com o objetivo de identificar pontos comuns em meio a uma diversidade de experiências, os chamados "tópicos translocais", como definidos por Ulf Hannerz.

De certa forma, pode-se argumentar que o termo "multilocal" [equivalente a múltiplos casos] é um pouco enganador, pois o que os projetos "multilocal" têm em comum é que eles se concentram em um problema, alguma formulação de um tópico, que é significativamente translocal, que não se restringe de um único lugar. (HANNERZ, 2003, p. 206, tradução livre).

Tabela 1 - Lista das experiências observadas, organizadas segundo seu vínculo institucional

\begin{tabular}{l|l}
\multicolumn{1}{c|}{ Mídia } & \multicolumn{1}{c}{ Organização } \\
\hline 1. Jornal Sem Terra & Movimento dos Trabalhadores Rurais Sem \\
2. Brasil de Fato & Terra - MST \\
3. Centro Popular de Mídias & * O MST é um dos movimentos sociais \\
4. Terra Vermelha & envolvidos na produção do jornal Brasil de \\
5. Rádio Conquista & Fato e na condução do Centro Popular de \\
\hline
\end{tabular}




\begin{tabular}{|c|c|}
\hline 6. Facebook Page Herdeiros da Terra & Mídias \\
\hline 7. Mídia Ninja & Coletivo Fora do Eixo \\
\hline $\begin{array}{l}\text { 8. Rádio Nova Paraisópolis } \\
\text { 9. Jornal Espaço do Povo }\end{array}$ & $\begin{array}{l}\text { Associação de Moradores de Paraisópolis } \\
* \text { O jornal Espaço do Povo é uma mídia } \\
\text { independente, mas apoiada pela associação } \\
\text { comunitária }\end{array}$ \\
\hline $\begin{array}{l}\text { 10. Jornal A voz do Lapenna } \\
\text { 11. Jornal Mundo Jovem Comunica }\end{array}$ & $\begin{array}{l}\text { Núcleo de Comunicação Comunitária São } \\
\text { Miguel no Ar (Fundação Tide Setubal) }\end{array}$ \\
\hline 12. Jornal de Chiador & Associação de Moradores de Chiador \\
\hline 13. Agência de Notícias das Periferias & Mural (Folha de São Paulo) \\
\hline 14. Énois & Énois Inteligência Jovem \\
\hline 15. Escola de Notícias & Escola de Notícias \\
\hline 16. Jornal Folha do Sabará & Comunidade Sabará \\
\hline 17. Escola de Comunicação Popular & $\begin{array}{l}\text { Centro de Formação Urbano Rural Irmã Araújo } \\
\text { - Cefuria } \\
* \text { O Cefuria é uma das organizações que } \\
\text { participa da realização da Escola de } \\
\text { Comunicação Popular }\end{array}$ \\
\hline 18. Jornal Fala, Mãe Luiza & $\begin{array}{l}\text { Centro Sócio Pastoral Nossa Senhora da } \\
\text { Conceição }\end{array}$ \\
\hline 19. Coletivo Nigéria & Nigéria Filmes \\
\hline $\begin{array}{l}\text { 20. Rádio FM Casa Grande } \\
\text { 21. Produtora Sem Canal }\end{array}$ & Fundação Casa Grande \\
\hline 22. Rádio Ibiapina & Associação de Moradores de Florânia \\
\hline 23. TV do Bem & Casa do Bem \\
\hline 24. local radio stations & Rede de Notícias da Amazônia \\
\hline $\begin{array}{l}\text { 25. Rede Mocoronga } \\
\text { 26. Rádio Floresta } \\
\text { 27. Blog de São Pedro } \\
\text { 28. Rádio Bem-te-vi }\end{array}$ & Projeto Saúde e Alegria \\
\hline 29. Rádio Lago & Comunidade do Lago Grande do Curuai \\
\hline
\end{tabular}

As experiências selecionadas combinam características comuns, que lhes dão unidade, e características específicas, que conferem diversidade ao conjunto (PATTON, 1990). As características comuns são que todas as mídias estão associadas a lutas sociais de distintas naturezas e abordagens; todas se situam em condição de periferia, o que diz respeito não apenas à localização geográfica, mas também à questão da segregação moral da sociedade (MARTINS, 2015); e todas envolvem mídias de longa duração, em oposição a 
plataformas de comunicação criadas exclusivamente para campanhas, protestos ou mobilizações, que deixam de existir ao final desses eventos. As características específicas se referem à região geográfica; à condição socioeconômica do contexto em que a mídia está situada; ao tipo de plataforma tecnológica utilizada; e ao tipo de vínculo institucional (Tabela 2).

Tabela 2 - Resumo das principais características das mídias populares observadas

\begin{tabular}{|ll|}
\hline Situação geográfica & Centros urbanos: 17 \\
& Meio rural: \\
& South: 5; Southeast: 12; North: 6; Northeast: \\
& 6 \\
\hline Alcance da audiência & Mídias comunitárias: 11; municipais: $8 ;$ \\
& regionais: 2; nacionais: 8 \\
\hline Tipo de plataforma tecnológica utilizada & Jornal impresso: 9; Rádio: 8; TV/vídeo: 3; \\
& Multimídia: 2; Página de Facebook ou blog: \\
& 2; Agência de notícias: 2 \\
& Programas de capacitação: 3 \\
\hline Uso de recursos digitais & Usam: $19 ;$ Não usam: 1 \\
\hline Vínculo institutional & Movemento Social: 1; ONG: 4; Empresa de \\
& mídia: 6; Associação Comunitária: $8 ;$ \\
& Fundação Corporativa: 1 \\
\hline Tempo de existência & Criada nos anos 1980: 3 \\
& $1990: 2$ : \\
& $2000: 10$ \\
& $2010: 9$ \\
\hline
\end{tabular}

A abordagem aos casos foi feita, principalmente, durante três visitas de campo, em outubro-novembro/2013, abril-maio/2014 e outubro-dezembro/2015. Nessas visitas, as práticas foram observadas e realizaram-se entrevistas com 55 comunicadores em posições de liderança nas iniciativas, valendo-se predominantemente de uma abordagem indutiva (KAUFMANN, 1996). Cada entrevista seguia uma ordem particular com os assuntos sendo conduzidos de acordo com o desenvolvimento da própria conversa. Havia, no entanto, 'pontos de discussão' que deviam ser abordados para responder à questão de pesquisa e avançar as hipóteses, assim como todo o processo analítico.

Esses 'pontos de discussão' podem ser definidos como assuntos que conectam as necessidades da pesquisa e as práticas observadas. Eram os tópicos iniciais, formulados de 
maneira simples e direta, e utilizados para introduzir as discussões durante as entrevistas. Sempre havia uma lista inicial de 'pontos de discussão', que era seguida e, ao mesmo tempo, transformada durante as conversas. Após cada conversa, eu confrontava minha lista inicial de tópicos com diários de campo, que continham minhas interpretações preliminares e percepções das atividades observadas e da(s) entrevista(s). Os pontos iniciais de discussão e outros, derivados desse confronto, constituíam, então, novos 'pontos de discussão' para as interações subsequentes. Na medida em que o processo analítico tomava forma, minhas interpretações iniciais passaram a constituir também 'pontos de discussão', que eu lançava nas conversas com os entrevistados para confrontar a evolução de minhas hipóteses com o campo. Esta é uma característica particular da teoria baseada nos fatos, que destaca uma atividade permanente de retornos entre observações, literatura e análises, como definido por Kaufmann. Nela, "uma estrutura particular de confrontação domina amplamente: trata-se do confronto permanente entre conhecimento local (categorias originais) e conhecimento global (conceitos abstratos)." [KAUFMANN, 1996, p. 84, tradução minha].

As mídias estudadas foram organizadas em três grupos, como casos principais, intermediários e secundários. Os principais foram abordados mais de uma vez - seja com mais de uma visita de campo ou com um conjunto mais amplo de entrevistados no decorrer da pesquisa. Os demais cumpriram papeis diferentes na saturação dos dados levantados no decorrer da pesquisa. A imersão a longo prazo é uma característica central da pesquisa etnográfica clássica, com visitas de campo que duram de meses a anos. Na pesquisa com múltiplos casos, a duração do tempo gasto em cada caso também é importante, mas se estrutura de acordo com o tipo de dados estimados necessários para discutir os "tópicos translocais" em questão. Neste sentido, a organização em três grupos de casos orientou também a abordagem durante as visitas de campo. É importante salientar que essas visitas não tinham a intenção de esgotar a análise sobre nenhum dos casos em específico, mas de aprofundar o máximo possível a compreensão dos "tópicos translocais".

Hannerz afirma que o tempo gasto junto a cada caso de um projeto de pesquisa de múltiplos casos deve ser observado sob diferentes perspectivas. Ele usa o exemplo de um estudo com correspondentes estrangeiros para dizer que não seria tão útil estar com esses profissionais em seus escritórios observando seu trabalho, enquanto eles estivessem em 
frente a um computador, lendo e escrevendo. "O que você faz quando 'seu pessoal' passa horas sozinho debruçado sobre uma mesa, talvez se concentrando em frente a uma tela de computador?", pergunta (HANNERZ, 2003, p. 212). Para ele, era melhor interagir com o maior número possível de correspondentes em cada local da pesquisa, para obter informações sobre diferentes práticas empregadas por eles em um mesmo contexto.

Para mim, da mesma forma, o objetivo não era observar os detalhes do processo de produção, embora algumas dessas observações fossem relevantes para entender as descrições feitas pelos comunicadores populares durante as entrevistas. Desta forma, as observações de campo sempre foram orientadas a aspectos que se relacionavam com os "tópicos de discussão" e com os "tópicos translocais". Igualmente, a grande maioria das entrevistas foi realizada nos locais de atuação dos comunicadores (o estúdio da rádio, o acampamento do MST, os espaços de reunião com a comunidade), de maneira a facilitar a contextualização e a exemplificação das informações compartilhadas.

De maneira geral, todos os casos foram, ainda, acompanhados durante todo o decorrer da pesquisa, por meio de suas atividades em redes sociais, para acompanhamento da evolução de suas estratégias e posicionamentos. Esse acompanhamento não tinha como objetivo análises das produções eletrônicas; ele serviu para corroborar ou problematizar aspectos observados nas visitas de campo e discutidos nas entrevistas. Em algumas situações, houve contatos por plataformas virtuais ou trocas de mensagens com os comunicadores, para esclarecimento de dúvidas que emergiam a partir da observação dessas atividades. Por exemplo, um dos comunicadores havia anunciado que sua mídia passaria a utilizar uma plataforma eletrônica para produção coletiva de conteúdos. Quando uma nova plataforma eletrônica foi anunciada em sua página de Facebook, esse comunicador foi consultado para verificar se era a mesma à qual ele havia se referido na entrevista e de que maneira ela correspondia às expectativas anunciadas anteriormente.

A pesquisa utilizou, predominantemente, uma análise qualitativa de dados. Observar o que as iniciativas têm em comum e o que é específico permite uma percepção crítica dos padrões mais amplos (sociais, institucionais e políticos) nos quais elas funcionam, seguindo a lógica dos trabalhos com múltiplos casos. A combinação entre elementos de unidade e de diversidade teve como objetivo dar consistência à análise de características comuns 
encontradas nos casos e, a partir delas, desenvolver reflexões mais generalizadas sobre a evolução do campo da comunicação e mídia popular no Brasil.

\section{Tecnologias rudimentares: entre fragilidade e estratégia}

De acordo com os estudos de caso analisados, mídias populares ainda se valem de muitas tecnologias baratas e rudimentares. Dois aspectos principais precisam ser ponderados para refletir sobre essa situação. Por um lado, além da análise crítica que denuncia as condições precárias de trabalho, é importante destacar a capacidade de agência por trás de algumas dessas decisões. Por outro lado, iniciativas mais bem estruturadas parecem mais frequentes do que as observadas por Peruzzo nos anos 1980 e 1990.

Condições precárias limitam concretamente a capacidade de ação dos atores sociais que desenvolvem mídias populares, mas a definição dessa fragilidade deve ser cuidadosamente estabelecida. A escolha da tecnologia não indica necessariamente sua fragilidade. Por exemplo, duas estações de rádio comunitárias na região amazônica, a Rádio Floresta e a Rádio Bem-te-vi, ambas membros da Rede Mocoronga, no Pará, utilizam o sistema de alto-falantes distribuídos pelas ruas e por pontos de referência (praças, quadras esportivas, etc.), assim como a rádio comunitária do acampamento do MST, Herdeiros da Terra, em Rio Bonito do Iguaçu, no Paraná. Durante as visitas de campo, no final de 2015, todas enfrentavam problemas relacionados à condição dos equipamentos. No Pará, baterias solares antigas tornavam ainda mais difícil manter o sistema de rádio em operação. A rádio Bem-te-vi já vinha sendo abastecida por energia elétrica proveniente do gerador da comunidade. $\mathrm{O}$ alto custo desta fonte de energia foi uma das principais razões para reduzir o tempo de transmissão. As baterias solares da Rádio Floresta ainda estavam funcionando, mas os comunicadores disseram que elas estavam em seu limite. Em ambos os casos, não havia uma solução iminente para o problema, pois as equipes precisariam preparar um projeto e procurar algumas agências e organizações de ajuda para buscar um financiamento.

No acampamento Herdeiros da Terra, o já antigo sistema de som estava desligado por problemas técnicos. Enquanto eu almoçava na casa de um dos comunicadores, um carro de som passou anunciando uma assembleia comunitária para o final daquele dia; era uma solução temporária para informar e mobilizar os militantes. Da mesma forma que os casos 
na região amazônica, não havia dinheiro disponível para consertar ou substituir os equipamentos da rádio. É preciso salientar que, nesses casos, a fragilidade reside na falta de condições para manter o equipamento funcionando e não na escolha dessas tecnologias simples. É importante evitar o equívoco das políticas públicas no Brasil, que determinam o tipo de tecnologia para a comunidade radiofônica como padrão para todo o país, sem levar em conta os reais contextos e necessidades das comunidades.

Jo Tacchi (2014) baseia seu conceito de "mobilidades significativas" (meaningful mobilities, no original em inglês), entre outras fontes, na análise do uso de telefones celulares por mulheres desfavorecidas na Índia. Para ela, os benefícios e limitações das plataformas tecnológicas estão diretamente associadas à complexidade dos contextos.

O modo como práticas de mídia e comunicação se relacionam com os lugares, espaços, relacionamentos, rotinas e cotidiano das pessoas é algo complexo e inter-relacionado. Assim, na comunicação para o desenvolvimento, seria útil pensar em contextualizar os benefícios. (TACCHI, 2014, p. 109-110).

Um dos membros da equipe de comunicação do MST explicou que as limitações impostas pela legislação de rádio comunitária no Brasil a tornam uma solução ruim para as estratégias de comunicação do movimento. Por exemplo, o acampamento Herdeiros da Terra faz parte do maior conjunto de assentamentos e acampamentos da América do Sul, reunindo cerca de 7.000 famílias. De acordo com a legislação, uma estação de rádio comunitária não pode exceder o alcance de um quilômetro em torno de sua antena (Brasil, Presidência da República, 1998), o que não é suficiente para tamanho território. Nessa situação, a simplicidade da antiga plataforma de alto-falantes não é a principal preocupação. A tecnologia barata e rudimentar realmente se encaixa no contexto e representa uma decisão estratégica.

[O modelo de] rádio comunitária não serve para nós. Você continua lutando por tantos anos por uma licença pública e, no final, não chega nem mesmo à comunidade, sem mencionar todas as limitações de patrocínio cultural, etc. (Entrevista com comunicador popular no MST, 2015).

Anastasia Kavada sugere que a agência, como a capacidade que os atores têm para agir e tomar decisões, deve ser levada em consideração em relação ao contexto em que uma ação social é desenvolvida (KAVADA, 2016). Esse princípio serve para guiar a análise sobre a evolução das mídias populares no decorrer do tempo. A qualidade não se revela, 
necessariamente, pelo acompanhamento das tendências tecnológicas, mas pela condição de acesso a elas, pela capacidade/liberdade de escolher aquelas que mais atendem às necessidades e pelas características das comunidades envolvidas com as mídias populares. Essa capacidade/liberdade de escolha revela assimetrias de poder nas dinâmicas de comunicação internas e externas às comunidades.

No que se refere à maior frequência de experiências bem estruturadas, em comparação com o quadro descrito por Peruzzo (1998), de maneira geral, é preciso considerar uma combinação de fatores que a influenciam. Por um lado, está a vulgarização de tecnologias, decorrente da digitalização e de estratégias comerciais que buscam ampliar o uso de aparelhos eletrônicos - a possibilidade de usar telefones celulares para gerar e transmitir informações é um exemplo. Por outro lado, ainda que frágeis e incompletos em comparação com as demandas apresentadas pela sociedade, houve avanços no que se refere à ampliação ao direito à comunicação - programas governamentais, como o chamado Ponto de Cultura, permitiram que muitas comunidades tivessem a oportunidade de produzir e difundir suas narrativas. Finalmente, mas igualmente importante, está a crescente valorização da integração de práticas de comunicação e mídia às estratégias de luta social, também favorecida pela oportunidade de visibilidade proporcionada por plataformas eletrônicas. A discussão apresentada a seguir, com foco nas diferentes plataformas tecnológicas, ilustra alguns aspectos particulares dessa evolução.

\section{A situação da mídia popular impressa}

A falta de estruturas básicas foi uma das situações observadas nas experiências de mídias populares impressas. Alguns comunicadores trabalham em salas cedidas por sindicatos, associações e igrejas, alguns não contam com espaço algum, muitos usam seus próprios computadores e telefones celulares, e a maioria menciona problemas para imprimir os jornais regularmente. O Jornal Sem Terra foi descontinuado durante o período desta pesquisa, principalmente por causa de seus altos custos e um complexo sistema de distribuição. Em 2013, na primeira entrevista com membros da equipe de comunicação do MST, um dos comunicadores na coordenação nacional relatou que várias edições recentes tinham sido suprimidas. Em 2015, sua última edição, datada de dezembro de 2014, foi 
distribuída. Os comunicadores mencionaram a intenção de manter o título da publicação e usá-lo em impressões comemorativas do movimento.

No entanto, no mesmo período, o jornal Brasil de Fato foi reformado e ampliou sua produção e distribuição de três capitais (São Paulo, Rio de Janeiro e Belo Horizonte) para cinco capitais (as anteriores mais Curitiba e Recife). O MST está entre os fundadores desse jornal e é membro de seu conselho editorial em alguns dos locais onde é produzido atualmente.

No que se refere aos impressos, o estudo revelou que a maior contribuição da incorporação de recursos digitais se concentra na possibilidade de ampliar e diversificar o público por meio do acesso a versões eletrônicas das publicações postadas em sites, blogs e redes sociais. Observou-se também uma melhora em relação à mobilidade e à interatividade. A mobilidade está relacionada ao uso de smartphones e outros dispositivos móveis na produção de artigos, permitindo inclusive a participação de comunicadores fora das comunidades. É o caso dos jornais Fala, Mãe Luiza, em Natal, no Rio Grande do Norte, e do Jornal de Chiador, em Chiador, Minas Gerais.

No primeiro caso, o editor do jornal já não mora na comunidade, mas ainda é o principal responsável pela redação e edição do jornal, tarefas que ele desenvolve em parte utilizando seu telefone, como ele descreveu, durante uma entrevista em novembro de 2015. O fundador do Jornal de Chiador tampouco vive mais nessa cidade, mas permanece como membro do comitê editorial do jornal da comunidade. O grupo se reúne por Hangouts, que ele descreveu, em junho de 2016, como uma solução que o ajuda a participar das atividades e também a motivar os próprios moradores a fazerem o mesmo. No caso do Jornal de Chiador, um comunicador relatou que existe um grupo de pessoas que não moram mais na cidade, mas ainda estão interessadas no que acontece e participam da produção do jornal por meio de plataformas eletrônicas. ${ }^{2}$

\footnotetext{
${ }^{2}$ Os princípios da comunicação popular preconizam que as mídias produzidas pelos grupos contem com a participação ativa e central de seus próprios membros, o que levanta uma questão a respeito da situação destes dois jornais, que têm membros de sua coordenação vivendo fora das comunidades. Este aspecto foi tratado criticamente em mais detalhe na dissertação, num debate concentrado em dinâmicas de participação, e estará em breve disponível em artigo no Brasil. Em resumo, essa análise sugere que o contexto atual de mobilidade requer novas perguntas e categorias de análise para discutir a participação nas mídias populares, de modo a observar os princípios de engajamento dos membros das comunidades associadas a essas mídias e novas dinâmicas, próprias da cultura associada a tecnologias digitais.
} 
A interatividade, por sua vez, significa a possibilidade de trocar informações com o público de maneira regular, diferente do que costumava acontecer com a versão exclusivamente impressa, em que as reações deviam esperar pela próxima edição para obter um espaço. Relatando evoluções desde a publicação de seu livro Radical Media, John Downing, destacou que "a mudança decisiva para melhor, na minha opinião, tem sido a capacidade de fazer e distribuir mídia e receber feedback" (DOWNING, 2016, p. 8). Alguns dos meios impressos observados usam as plataformas digitais para promover uma dinâmica de continuidade nas notícias. Uma atividade anunciada em uma edição impressa pode ser atualizada on-line de acordo com seu desenvolvimento e envolvendo a participação do público.

Em nenhum dos casos, o acesso a recursos digitais parece ter mudado o contexto de instalações rudimentares. E, mais importante, mesmo se equipamentos de alta qualidade foram observados em várias das experiências analisadas, isso não significa que foi fácil obtê-los. Eu não vi nenhum grupo fazendo cópias de um jornal a partir de folhas onde os artigos foram originalmente recortados e colados - como era o caso de produções artesanais, alguns anos atrás. A difícil tarefa de imprimir com regularidade foi, no entanto, mencionada em todas as regiões visitadas. O custo da impressão em si representa um importante obstáculo, que se soma à capacidade de distribuição, tanto mais complexa e custosa quanto maior é a abrangência da comunidade a que se dirige o impresso.

Neste contexto, destacando a agência por trás da escolha da plataforma tecnológica, os recursos digitais figuram também como uma solução temporária para sanar algumas dessas crises. O jornal comunitário Fala, Mãe Luiza, converteu-se em uma plataforma digital em 2008 por razões econômicas. Em 2013, voltou a imprimir em papel para responder à necessidade de informação para todos os públicos da comunidade, algo que ainda não pode ser alcançado por meio das tecnologias digitais.

$\mathrm{Na}$ nossa comunidade, há muitas pessoas que não têm acesso à internet, os idosos, por exemplo. E tentamos alcançar todas as pessoas. Distribuímos nas igrejas, nas escolas, nas unidades de saúde, porque há pessoas que querem isso [o papel impresso]. Mas a mídia impressa no Brasil, atualmente, é uma luta. É difícil de fazer. (Entrevista com comunicador popular em Natal [RN], 2015). 
De acordo com a pesquisa, jornais impressos mantêm a relevância por razões práticas e estratégicas. Eles circulam nos territórios locais como um documento em que as pessoas podem verificar a agenda, conhecer os serviços locais e saber como usá-los, descobrir perfis de vizinhos ou conhecidos. Estão disponíveis em pontos de encontro como unidades de saúde e educação, restaurantes, igrejas e comércio; entram nas casas e são lidos pouco a pouco durante o mês, por toda a família.

Os jornais impressos lidam com os limites da alfabetização no campo, pois podem ser lidos em família ou em grupos. Mas eles também são usados para atingir grandes audiências, como propõe o renovado projeto editorial do jornal Brasil de Fato, mencionado acima. A publicação original ficou reconhecida por seus artigos densos, mais orientados a intelectuais de esquerda e militantes. Desde 2013, o grupo de movimentos sociais por trás da iniciativa mudou seu formato e linha editorial para falar com pessoas comuns por meio de um tabloide distribuído gratuitamente em várias capitais do país. Uma comunicadora envolvida com o jornal Brasil de Fato, em Minas Gerais, explicou que o jornal impresso ainda é o melhor meio para chegar aos trabalhadores e tem a vantagem de acompanhar outras ações desenvolvidas pelas organizações sociais nas bases: "ele chega vivo às pessoas". Para ela, é necessário analisar a promessa de democratização que vem com o digital de maneira crítica, pois "a internet ainda não chega a todos e, mais importante, o conteúdo hegemônico ainda é o mais acessado nessas plataformas".

\section{Um passo à frente em relação às produções em vídeo}

Entre os estudos de caso, apenas alguns grupos lidam com a produção de televisão ou vídeo regularmente. A única produtora de vídeos para um canal regular de televisão é a TV Sem Canal, vinculada à Fundação Casa Grande, em Nova Olinda, no Ceará. O grupo montou um estúdio com equipamentos para operar uma televisão comunitária regular, mas não obteve a concessão para transmissão (até o fim desta pesquisa). Desde então, vinham produzindo peças sobre cultura e pessoas da região para a TV Futura. As peças também eram transmitidas no teatro mantido pela Fundação. Toda vez que havia um concerto ou outra atração cultural, eles aproveitavam a oportunidade para exibir as produções de vídeo. 
Todos os outros estudos de caso trabalhando com vídeo têm uma conexão próxima com plataformas digitais. A Mídia Ninja e o Coletivo Nigéria ganharam notoriedade nacional por suas produções em vídeo durante as manifestações de 2013 (SUZINA, 2014). A TV do Bem é um canal digital de vídeo comunitário em Natal, no Rio Grande do Norte, que vem registrando o cotidiano do bairro periférico de Mãe Luiza. Apesar dos diferentes projetos editoriais e formatos escolhidos, estas três iniciativas usam plataformas virtuais para difundir suas produções. A equipe de comunicação no assentamento Herdeiros da Terra também produz vídeos para sua página no Facebook, enquanto o MST vem profissionalizando sua produção de vídeo em um esforço nacional.

Os casos da Mídia Ninja e do Coletivo Nigéria incorporam uma abordagem mais direta das produções audiovisuais carregadas de mensagens de mudança social para a sociedade em geral. Eles não são uma novidade completa. Desde a década de 1960, o desenvolvimento de tecnologias mais baratas, portáteis e de manipulação/operação mais fácil levou ativistas em várias partes do mundo a usar o audiovisual como recurso nas lutas (CARDON \& GRANJON, 2013, p. 36-42). No contexto da presente pesquisa, todas as iniciativas observadas possuem bons equipamentos; algumas têm equipamentos efetivamente muito bons. Seguindo a evolução histórica, a edição torna-se mais barata e mais amigável em plataformas virtuais - alguns comunicadores até atribuem o poder de suas produções à total falta de edição, ao efeito de verdade das transmissões. Isso significa que, por um lado, atores de mudança social podem produzir peças de melhor qualidade e, por outro lado, a demanda por qualidade abriu mais espaço para a relevância da informação.

No entanto, a tendência atual traz uma nova luz para o antigo debate sobre o que caracteriza, sobre o que distingue de maneira particular projetos de mídia popular. Em 2001, Alfonso Gumucio-Dagron lançou um debate sobre os mitos e paradigmas da comunicação participativa (GUMUCIO-DAGRON, 2001), destacando os aspectos de escala, visibilidade e pureza. Particularmente, em relação à escala e à visibilidade, esses mitos associavam a comunicação participativa a uma circulação restrita em territórios geográficos e espaços de intervenção associados às ações, e, portanto, visíveis/acessíveis prioritariamente ou exclusivamente dentro desses circuitos. Desse modo, limitação na 
circulação era tomada como uma característica da comunicação participativa, problematizando pouco uma restrição de duplo sentido, isto é, a dificuldade que esses grupos tinham para alcançar públicos e estabelecer diálogos, assim como a dificuldade de diferentes públicos para ter acesso a informações produzidas de forma alternativa.

Na perspectiva da limitação, a ruptura digital permitiu não somente ultrapassar uma importante barreira, por meio de transformações na capacidade de edição, mencionadas acima, mas também superar problemas de capacidade de distribuição. Neste caso, antes, a distribuição da produção audiovisual popular dependia de redes estabelecidas de televisão ou cinema para atingir públicos que ainda não estavam engajados. Diferentes plataformas e dispositivos eletrônicos permitiram tornar disponível, com poucos ou inexistentes entraves de filtro e custo, todo tipo de produção audiovisual.

[...] o advento do YouTube em 2005 foi de fato um fator de mudança de distribuição, com destaque para a disponibilidade de seu arquivo pesquisável. Acesso a uma vasta quantidade de informações sem censura, acesso à postagem, multilinguismo: essas dimensões - embora cerceadas pelas regras de propriedade intelectual - geram possibilidades surpreendentes. (DOWNING, 2016, p. 8).

Finalmente, é importante mencionar que Mídia Ninja e Coletivo Nigéria não emergiram de uma comunidade marginalizada ou de uma organização social particular. No primeiro caso, a origem é um coletivo cultural de âmbito nacional, que envolve jovens interessados e capazes de produzir informações a partir de seus territórios e difundi-las por meio de diferentes plataformas digitais. No segundo, é uma iniciativa de jovens jornalistas que moram e trabalham em apartamentos e escritórios de classe média em Fortaleza, no Ceará. Suas produções são, no entanto, completamente dedicadas a questões que afetam grupos sociais periféricos e são produzidas em estreito diálogo com elas (ver estudo de caso, a seguir).

Essas iniciativas rompem outro mito, que se refere à propriedade das mídias populares, e se conectam à tendência desencadeada durante as demonstrações de 2013, em que plataformas de mídia engajadas trabalharam para destacar visões de mundo alternativas. Cobrindo as lutas sociais ou produzindo materiais em parceria com atores de mudança social, elas têm impulsionado a cultura de usar o audiovisual para confrontar mensagens hegemônicas com conteúdos próprios. Numa entrevista concedida em São 
Paulo, em novembro de 2015, uma das comunicadoras no Centro Popular de Mídias revelou uma percepção pessoal de uma quantidade crescente de atores fazendo vídeo com qualidade profissional. Esse centro acompanha e apoia a comunicação e produções midiáticas de vários pequenos e grandes movimentos sociais em todo o país. Em entrevistas diferentes em 2013 e 2015, membros da equipe de comunicação do MST falaram da criação de narrativas para forjar debates e de um objetivo de se tornarem fonte de conteúdo pronto sobre as mobilizações. Membros da Mídia Ninja e do Coletivo Nigéria falam, mais ou menos formalmente, de treinar seus parceiros na linguagem da mídia para fortalecê-los. Além disso, se o Coletivo Nigéria sempre privilegiou materiais cuidadosamente editados, a Mídia Ninja começou com transmissões sem corte e sem edição, e evoluiu para produções mais elaboradas.

Se, por um lado, a evolução no campo audiovisual representa oportunidades para os atores da mudança social, destaca-se também a relação assimétrica na esfera midiática brasileira. Se a qualidade e a distribuição não podem mais ser apontadas como fatores relevantes para distinguir e recusar as produções da mídia popular, o argumento do amadorismo ainda é usado, e o filtro cultural e ideológico emerge mais claramente (SUZINA, 2016).

\section{Estudo de caso: $O$ Coletivo Nigéria e a pedagogia da televisão}

O Coletivo Nigéria é um coletivo de jovens jornalistas que ganhou notoriedade durante as manifestações de 2013, cobrindo os protestos nas ruas de Fortaleza, no Ceará. Eles eram quatro membros, na época da primeira visita de campo, em novembro daquele mesmo ano, e se tornaram três em 2015, época da segunda entrevista, contando também com equipes temporárias de acordo com as demandas. Outra transformação, nesse período, foi a definição de uma preferência clara por produções audiovisuais, em parceria com movimentos sociais, ONGs e outros atores sociais.

Primeiro, se temos alguma força, essa é a nossa força [o audiovisual], muito mais do que outras linguagens. Mas o audiovisual em si é uma linguagem universal, porque é a linguagem da imagem. A linguagem escrita não é universal, é uma linguagem muito sectária, especialmente em um país onde há muitas pessoas analfabetas. [...] Entendemos que a linguagem audiovisual é mais flexível para se 
adequar a diferentes perfis de públicos. $\mathrm{E}$ é a linguagem do Brasil. O povo brasileiro, desde muito cedo, está influenciado pela pedagogia da televisão, da novela. Fomos forjados pela linguagem da televisão e agora pela internet, que abriu outro mundo. Tem muito mais possibilidades, mais dinamismo, mas ainda ali, a linguagem predominante é o visual, o audiovisual. (Entrevista com comunicador popular, Coletivo Nigéria, 2015).

Esses três midiativistas administram o que poderia ser descrito como uma pequena empresa de produção audiovisual que, em 2013, eles mesmos descreveram como uma produtora capaz de ganhar dinheiro suficiente para apoiar financeiramente projetos militantes gerenciados pelo coletivo. Em 2015, um deles admitiu que eles se apresentam e se sentem mais identificados como um coletivo e que seu trabalho principal é produzir audiovisuais para empoderar movimentos sociais com a mesma qualidade daqueles feitos por grandes empresas. Eles não estão ligados a nenhum movimento ou comunidade específica, mas definem seu trabalho como ideológico e o associam à luta pela ocupação da esfera pública.

As produções do Coletivo Nigéria incluíam, durante o período desta pesquisa, documentários, filmes e séries sobre questões sociais e lutas territoriais, que foram distribuídos pela internet, cinemas e DVDs. O nome Nigéria foi escolhido como uma referência ao popular mercado audiovisual na Nigéria, baseado em produções baratas e distribuídas por simples cópias em DVD por todo o país africano. A escolha do canal de distribuição para cada produção é feita com base na intenção da ação. A internet é usada para questões que exigem ampla e rápida distribuição. Cinemas e cópias em DVD são escolhidos para alcançar públicos segmentados com peças que tenham apelo de exclusividade. Isso porque, embora eles entendam a importância de produzir material que apoie mobilizações atingindo pessoas já engajadas, o grupo dedica uma atenção especial ao diálogo com a sociedade em geral, especialmente a classe média.

A suingueira é um dos movimentos mais fortes das periferias atualmente. $\mathrm{Na}$ verdade, é um movimento associado à identidade. Eu acho que ela está ocupando uma parte do espaço que pertenceu ao rap. Os jovens se afirmam através da suingueira. E isso não está na mídia, é algo pertencente à periferia. [...] Nosso papel é levar as insurgências que acontecem nas periferias e trazê-las para a classe média. A classe média é alienada e não sabe o que acontece em sua própria 
cidade. Ela vive em um casulo. Fortaleza está em guerra. [...] O extermínio da juventude está acontecendo o tempo todo, despejos estão acontecendo o tempo todo. Nosso papel é trazer [à tona] essas questões que não são cobertas pela grande mídia. (Entrevista com comunicador popular, Coletivo Nigéria, 2015).

Um dos comunicadores do Coletivo Nigéria faz duas distinções importantes. Primeiro, os movimentos sociais não são clientes, mas parceiros. Eles constroem a mensagem e o produto juntos. Em segundo lugar, o trabalho não deve ser separado da satisfação de fazer algo relevante. Para ele, há muito trabalho a fazer no campo da mudança social e todos são interessantes, mas a profissionalização da produção audiovisual neste campo deve manter a conexão com um forte princípio ideológico. Ele afirma que seu objetivo é fazer com que o público sinta o mesmo que eles sentem, que um despejo fere todos os cidadãos, que o rosto sofrido de uma criança é responsabilidade de todos.

O uso do audiovisual merece uma observação cuidadosa na evolução da mídia popular por duas razões principais. De um lado, as tecnologias digitais aumentaram o acesso e simplificaram sua apropriação, já que equipamentos como smartphones podem ser utilizados para gravação, edição e difusão de conteúdos audiovisuais. Individual e coletivamente, a produção de peças audiovisuais surge como parte importante do processo de subjetivação através da palavra, através da expressão de narrativas pessoais. Por outro lado, de forma complementar, essa apropriação tem impacto em um contexto de relações de poder assimétricas, desde que as produções audiovisuais populares estejam interessadas em superar as barreiras práticas e simbólicas da circulação territorial e segmentada. O primeiro documentário de Coletivo Nigéria, um filme chamado ComVandalismo ${ }^{3}$, que discute a ideia de vandalismo no contexto das manifestações de 2013, teve mais de 250.000 visualizações no YouTube. O curta-metragem sobre ciclovias na cidade de Fortaleza teve mais de 100 mil visualizações em quatro dias, após seu lançamento, e seu documentário DefensorXs ${ }^{4}$, sobre ativistas de direitos humanos, levou 1.750 pessoas - público pagante ao cinema, em Fortaleza, durante quase 15 dias.

\section{A situação das rádios comunitárias}

\footnotetext{
${ }^{3}$ http://www.nigeriafilmes.com/project/com-vandalismo/. ${ }^{4}$ http://www.nigeriafilmes.com/project/defensorxs/.
} 
As imposições técnicas da lei de radiodifusão comunitária (Lei n ${ }^{\circ}$ 9.612/98) podem ser apontadas como uma das razões para a observação de um grande número de iniciativas mais bem estruturadas, comparadas às experiências analisadas por Peruzzo, nas décadas de 1980 e 1990. Apesar da engessada definição de padrões que estações de rádio e televisão comunitárias devem seguir em diversos lugares do país, a legalização das rádios comunitárias desempenha um papel importante em relação à qualidade do equipamento. Como quatro das oito estações de rádio da amostra são legalizadas, elas trabalham com antenas, transmissores, mesas de som e microfones tecnologicamente adequados. Porém, duas coisas precisam ser mencionadas e se aplicam a todo tipo de iniciativas. A primeira é o enorme esforço para obter o equipamento necessário. A segunda é que manter até estruturas básicas ainda representa um grande desafio no contexto da comunicação popular.

Entre as estações legalizadas da amostra, a Rádio Ibiapina, em Florânia, no Rio Grande do Norte, ilustra bem essa situação. Durante minha visita de campo em outubro de 2013, um comunicador envolvido com a rádio comunitária explicou que obter todo o equipamento necessário foi mais difícil do que obter a licença em si. A história desta rádio começou em 2002, sob os auspícios da Igreja Católica na cidade. O padre era advogado e político, o que ajudou nos procedimentos legais. Muitas atividades de arrecadação de fundos foram promovidas ao longo dos anos para comprar e substituir equipamentos, muito caros para as condições locais.

O equipamento, naquele momento em que foi comprado, era um kit concebido para estações de rádio comunitárias. Compramos uma mesa de som, dois microfones, a antena, o transmissor e o retorno. Depois de um tempo, veio uma inspeção da Anatel e nosso transmissor não foi aprovado. Eles nos deram 30 dias para trocar o transmissor. Foi quando ficou muito difícil, porque não tínhamos o dinheiro. [...] Então, com toda a nossa coragem, iniciamos outra campanha para mudar o transmissor e organizamos um bingo, porque naquela época era permitido, diferente de hoje. Tivemos o bingo e coletamos mil e poucos, mas o transmissor, apenas o transmissor, custava dois mil. Então conseguimos alguma ajuda e compramos o transmissor autorizado pela Anatel. No entanto, quando chegamos aqui e ligamos, felizes da vida, foi quando descobrimos que o transmissor não era estéreo, era mono. Então ligamos para os caras da Apel, em Campina Grande. Eles disseram sim, o transmissor é mono e agora você precisa 
comprar o gerador de sinal estéreo. Só este gerador custava outros 800. Trabalhamos seis meses em sistema mono, sem nenhuma qualidade. Depois, tinha um padre que era nosso amigo, padre Welson, que havia trabalhado em Florânia e é um apaixonado do rádio. Ele é de Currais Novos e viu a nossa mobilização, e disse 'vou conseguir esse gerador para vocês' e ele conseguiu. Quinze dias depois, tínhamos nosso gerador de sinal estéreo. Então, tudo ficou bem. (Entrevista com comunicador popular, Rádio Ibiapina, 2013)

Exceto pela vantagem de contar com um padre advogado e político, a maioria das rádios comunitárias da amostra compartilha a mesma experiência de usar vários tipos de ações de angariação de fundos para ter todos os equipamentos de produção e transmissão necessários. Outro desafio compartilhado é a estrutura básica: encontrar uma sala; pagar contas regulares de eletricidade, água e telefone; conseguir mesas, cadeiras e todos os móveis. As soluções incluem o uso de salas concedidas por igrejas e associações locais, mobiliário antigo e reparado, e até pertences pessoais trazidos pelos próprios comunicadores - que são regularmente voluntários. Durante a pesquisa de campo, senteime em cadeiras quebradas, entrevistei pessoas usando um ventilador muito barulhento para refrescar um dia muito quente, pisei em terra batida dentro de um estúdio, ouvi histórias sobre chover dentro dos estúdios, sobre os equipamentos etc.

Em geral, as políticas relativas às rádios e às emissoras de televisão comunitárias são fortemente criticadas por comunicadores e acadêmicos nesse campo (BERTI, 2014; GOMES, 2015; ROSEMBACH, 2015; GONÇALVES, 2015). Mesmo reconhecendo que a regularização melhora as condições estruturais, por causa dos requisitos obrigatórios, a mesma lei não vincula características tecnológicas a necessidades contextuais (como as mencionadas antes, para comunidades territorialmente dispersas) nem permite o apoio financeiro por meio de algum tipo de comercialização.

Tanto quanto seus pares em outras iniciativas, os comunicadores populares da comunidade de Paraisópolis, na cidade de São Paulo, descreveram uma situação que mostra os desafios permanentes para manter uma iniciativa viva: trabalhar principalmente com voluntários, sob pressão vinda de diferentes grupos da comunidade em relação à distribuição de programas, ante o já mencionado custo de atualização de equipamentos, a necessidade de treinamento para o pessoal e a permanente falta de recursos financeiros, que 
conecta e aprofunda todos e cada um desses desafios. De acordo com a lei que rege as rádios comunitárias no Brasil, esse tipo de iniciativa não pode ter nenhuma atividade comercial, o que inclui publicidade. Eles devem sobreviver de doações e do que a maioria deles chama de apoio cultural, que é um tipo de patrocínio vindo de atores privados.

Para uma comunicadora atuante na rádio comunitária de Paraisópolis, "a legalização é incompleta", porque não oferece às rádios comunitárias os mesmos direitos concedidos a outras categorias de rádio. Além disso, o governo, que é responsável pela política, tampouco apoia a atividade.

Se o governo desse um décimo do que dá para as rádios comerciais [em publicidade], as rádios comunitárias poderiam sobreviver melhor $\mathrm{e}$ as informações relativas às políticas públicas atingiriam mais facilmente o público correto. (Entrevista com comunicadora popular, Rádio Nova Paraisópolis, 2014).

Durante uma segunda visita de campo, em novembro de 2015, as condições de trabalho na Rádio Claro Nova Paraisópolis haviam melhorado muito, graças a uma parceria com uma empresa de telecomunicações. Em uma decisão inusitada, os reguladores autorizaram a parceria, que inclusive alterou o nome da emissora para incluir nele o nome da empresa "Claro", desde que o acordo não envolvesse publicidade de produtos. Esse patrocínio permanente garantiu à rádio comunitária melhores estúdios, equipamentos e uma conexão de internet estável. Segundo um dos comunicadores, "estabilidade significa liberdade". Desde que a estrutura básica esteja garantida, eles podem procurar patrocínio cultural para melhorar cada programa e manter a política de não vender tempo no ar. "Se a hora no ar estiver à venda, o cara com uma boa ideia e sem dinheiro não poderá fazer o seu programa”, explica o comunicador. Todos os locutores da rádio são voluntários e estão autorizados a buscar patrocínio cultural para seus programas específicos, recebendo $60 \%$ do subsídio e dando $40 \%$ como contribuição para a rádio.

A pesquisa exploratória em preparação para a presente pesquisa destacou uma tendência que não se confirmou em seu desenvolvimento. Em relação às emissoras de rádio, alguns casos observados de maneira exploratória sugeriram que as rádios web estavam surgindo como uma solução para superar as barreiras legais e melhorar a qualidade dos equipamentos com baixos custos (SUZINA, 2015). Nenhum dos estudos de caso da presente amostra utilizava esse recurso. Considerando as condições de vida das audiências 
conectadas com as mídias populares, os supostos benefícios da tecnologia digital, permitindo que todos se comuniquem, devem ser observados com cuidado. Se é verdade que as rádios web, por exemplo, são mais baratas que as emissoras de rádio tradicionais, as primeiras ainda não satisfazem as necessidades das comunidades que vivem em locais com pouca ou nenhuma conexão digital de qualidade (SUZINA, 2018).

\section{Conectando os povos amazônicos: O caso da Rede de Notícias da Amazônia}

Eu estive no Acre, pela primeira vez, no início dos anos 2000, para uma capacitação oferecida a comunicadores locais e líderes comunitários. Eu sabia que o rádio era reconhecido como o meio mais eficaz de comunicação naquela região, atingindo comunidades distantes umas das outras, independentemente da disponibilidade de energia elétrica e dos níveis de alfabetização. Durante uma visita a uma estação de rádio na capital Rio Branco, fiquei impressionado ao ouvir um programa em que o radialista lia mensagens de pessoas que queriam manter suas famílias e parentes atualizados sobre questões e situações privadas: "Maria da comunidade X, seu sobrinho José avisa que chegou bem” ou "Família Silva da comunidade Y, Sônia diz que Benito saiu do hospital e está se recuperando da operação”.

Ainda existem muitos programas como este na Amazônia. Por muitos anos, o rádio também foi usado para alfabetização à distância em áreas remotas como a região amazônica e o interior brasileiro. No entanto, embora o rádio seja reconhecido como essa plataforma geralmente acessível, a qualidade e o desenvolvimento de outras tecnologias ainda são muito importantes para sua operação. A Rede de Notícias da Amazônia é formada por 15 estações de rádio locais que operam na região amazônica ${ }^{5}$; ela produz um programa diário e uma rádio-revista semanal, com contribuições dos membros nos diversos estados. A maioria dessas rádios transmite ou transmitiu tais programas de "mensagens" e outros com finalidade educacional. Nesta experiência, a introdução de tecnologias digitais representou a oportunidade de estabelecer uma rede para produzir e compartilhar informações. Mas a fragilidade estrutural continua impondo limites ao projeto.

\footnotetext{
${ }^{5}$ Composição à época da realização da pesquisa.
} 
O dia que passei na Rádio Rural de Santarém, que abriga a sede da iniciativa, foi um dia de sorte. A banda larga estava estável o suficiente para receber as contribuições de todos os membros e enviar o programa editado, preparado por sua editora. Segundo ela, nem sempre é assim. Obter produções diárias de todos os membros constitui um desafio para a rede, considerando que as emissoras envolvidas precisam conciliar esse trabalho com as demandas de todas as outras produções permanentes em suas rádios locais. Quando um deles produz uma reportagem, mas é incapaz de colocá-la no programa diário, porque não há conexão com a internet para mandá-la a Santarém, a equipe lamenta o prejuízo. E a situação se torna ainda mais delicada quando todas as matérias são enviadas, a edição está pronta no horário e não há conexão para redistribuir o programa completo para os membros. "Aconteceu várias vezes", observou a editora. Uma associação latino-americana lhes ofereceu a possibilidade de usar seu satélite para distribuir as produções, mas eles acharam difícil organizar a rotina, considerando a diferença de horário entre todos os membros. Ter seu próprio servidor é uma solução muito cara para o grupo. A troca de $e$ mails é, portanto, a opção mais acessível e eficaz para envio de conteúdo. "Às vezes, divido o programa em várias partes, para que ele possa ir mesmo que a conexão seja ruim", explicou a editora. Apesar dessas limitações, a conectividade possibilitou que "o povo amazônico conversasse com o povo amazônico", como o fundador da rede descreveu como objetivo principal do projeto.

A Rede de Notícias da Amazônia é um bom estudo de caso para falar de condições para o desenvolvimento de mídias populares, pois tem a incorporação de tecnologias digitais entre seus principais recursos e limitações simultaneamente. Equipes reduzidas em cada uma das emissoras associadas enfrentam dificuldades para encontrar tempo para produzir peças regularmente para o programa diário da rede. Finalmente, a qualidade do equipamento varia de uma rádio para outra, o que produz alguns problemas no momento de editar os materiais e torná-los adequados a um programa diário comum.

Todos os membros são estações de rádio comerciais e/ou católicas e/ou educativas na região, o que significa que estão relativamente bem estruturadas. Um dos comunicadores na liderança da iniciativa disse que o grupo gostaria de incorporar rádios comunitárias à rede, mas isso tornaria as fragilidades mencionadas ainda mais profundas. As rádios 
comunitárias visitadas na região ilustram essa preocupação. A Rádio Floresta, em São Pedro, e a Rádio Beija-Flor, em Maripá, sofriam com a falta de baterias para fornecer energia para os equipamentos. Em Maripá, a equipe procurava novos voluntários para manter uma produção regular própria. A Rádio Lago, no Lago Grande do Curuai, tinha apenas um gravador para o uso de todas as equipes produzindo programas.

Todos os locais visitados também confirmaram que a teoria por trás da Rede de Notícias da Amazônia está correta. Eu me desloquei por comunidades que pertencem a Santarém, mas estão a muitas horas de barco distantes dela. Todas as pessoas mencionaram a Rádio Rural de Santarém como referência para obter informações. Os programas da rede têm, então, o potencial concreto de fornecer a essas audiências notícias vindas de outros estados da região, mas ainda assim produzidas por comunicadores locais - em oposição à produção midiática predominante vinda de redes situadas longe da região amazônica. Melhores condições de ação poderiam melhorar essa capacidade, integrando ao mesmo tempo mais provedores locais de informação e emissoras, e consequentemente mais perspectivas locais estariam disponíveis para diversificar o debate público.

\section{Considerações finais}

A evolução da incorporação de tecnologias nas experiências de mídias populares no Brasil apresenta grandes avanços em relação ao quadro exposto por Cicilia Peruzzo, em relação aos anos 1980 e 1990. Muitas das iniciativas analisadas estão dotadas de equipamentos de boa qualidade e, particularmente, a apropriação de recursos digitais vem permitindo superar alguns obstáculos estruturais de maneira eficiente, principalmente no campo da produção audiovisual.

Essa evolução não elimina, porém, situações rudimentares de uso das mídias por movimentos sociais, ONGs e associações comunitárias. Por um lado, essa condição é sinônimo de desigualdades estruturais que mantêm, historicamente, esses grupos em posição assimétrica no debate público. Ainda que o acesso a recursos tecnológicos represente oportunidades para o desenvolvimento da mídia popular, questões associadas à legitimidade das vozes interferem na possibilidade de sua inclusão plena. 
Por outro lado, a pesquisa mostrou que é importante observar a questão da qualidade dos materiais a partir da perspectiva da agência. Em alguns casos, tecnologias ditas rudimentares podem ser estrategicamente mais eficientes em relação aos objetivos dos grupos ou às condições de vida das audiências.

A incorporação de tecnologias na prática de mídias populares se revela, portanto, como fruto do contexto e como elemento político, com implicações internas e externas às comunidades associadas a essas mídias. Internamente, ela tem um papel preponderante na criação e na manutenção de canais de construção dessas mídias e de acesso a suas produções. Em geral, as condições estruturais para o desenvolvimento de mídias populares revelam a importância das políticas distributivas e de reconhecimento ao direito à comunicação. A falta de recursos é um problema de primeira ordem para todos os grupos dispostos a expressar suas vozes no debate público e desempenha um papel concreto no contexto da concentração da mídia, pois inibe as iniciativas e reforça as desigualdades e assimetrias. 


\section{Referências Bibliográficas}

BERTI, O. Rádios Comunitárias na Internet: Novas possibilidades cidadãs no status das tecnologias atuais. Mídia e Cotidiano, Dossiê Comunicação e Cidadania, n. 5, p. 1-18, dez. 2014.

BRASIL, Presidência da República. Regulamento do Serviço de Radiodifusão Comunitária. Decreto n. ${ }^{\circ}$ 2.615. Brasília, DF, 03 jun. 1998.

CARDON, D.; GRANJON, F. Médiactivistes. 2. ed. Paris: Presses de SciencesPo., 2013. COGO, D. Da comunicação rural aos estudos de audiência: influências da obra de Paulo Freire. $\quad$ out. $2009 . \quad$ Disponível em http://pvnocampo.com/artigos Ver.php?artigo_id=28. Acesso em: 18 jun. 2016.

DOWNING, J. D. Personal reflections on 50 years of radical media. Journal of Alternative and Community Media, v. 1, p. 7-9, 2016.

FESTA, R. Comunicação popular e alternativa: a realidade e as utopias.290 f. Dissertação (Mestrado em Comunicação Social)-Instituto Metodista de Ensino Superior, São Bernardo do Campo, 1984.

GIMENEZ, G. Notas para una teoría de la comunicación popular. In Que es la comunicación popular y alternativa?: Dos documentos para discusión. 2. ed., v. 1. ECO Servicio de documentación: comunicación y solidariedad, 1984.

GOMES, A. L. Dificuldades e tendências na trilha das rádios comunitárias. In PERUZZO, C. M.; OTRE, M. A.. Comunicação Popular, Comunitária e Alternativa no Brasil. Sinais de resistência e de construção da cidadania. São Bernardo do Campo: Universidade Metodista de São Paulo, 2015. p. 349-364.

GONÇALVES, R. J. A experiência da Rádio Comunitária Heliópolis. In PERUZZO, C. M.;OTRE, M. A. Comunicação Popular, Comunitária e Alternativa no Brasil. Sinais de resistência e de construção da cidadania. São Bernardo do Campo: Universidade Metodista de São Paulo, 2015. p. 648-656. 
GONZÁLEZ, J. A.. Sociología de las culturas subalternas. México: UABC, 1990.

GUMUCIO-DAGRON, A. Call me Impure: Myths and Paradigms of Participatory Communication. ICA Pre-Conference on Alternative Media “Our Media, Not Theirs". Washington DC, 2001.

HANNERZ, U. Being there . . . and there . . a and there! Reflections on multi-site ethnography. Ethnography, v. 4, n. 2, p. 201-216, 1990.

KAUFMANN, J.-C. L'entretien compréhensif. Paris: Nathan, 1996.

KAVADA, A. Social Movements and Political Agency in the Digital Age: A Communication Approach. Media and Communication, v. 4, n. 4, p. 8-12, 2016.

OTRE, M. A. Comunicação popular, alternativa e comunitária: um olhar sobre 40 anos de pesquisas no Brasil. São Paulo: Fundação Juscelino Kubitschek, 2016.

PATTON, M. Q. Designing Qualitative Studies. In , Qualitative evaluation and

Research methods. Beverly Hills, CA: SAGE, 1990. p. 169-186

PERUZZO, C. M. Conceitos de comunicação popular, alternativa e comunitária revisitados. Reelaborações no setor. Palabra Clave, v. 11, n. 2, 2008.

. Comunicação nos Movimentos Populares. Petrópolis: Vozes, 1998.

ROSEMBACH, C. J. Rádio Cantareira: Proposta de participação comunitária na prática. In PERUZZO, C. M.; OTRE, M. A. Comunicação Popular, Comunitária e Alternativa no Brasil. Sinais de resistência e de construção da cidadania. São Bernardo do Campo: Universidade Metodista de São Paulo, 2015. p. 635-647.

SUZINA, A. C. Digital disruption in popular media practices in Brazil. Commons. Revista de Comunicación y Ciudadanía Digital, v. 7, n. 1, p. 172-192, 2018.

. Digital resources in popular media practices in Brazil: strategies to reduce asymmetries in the public debate. Observatorio (OBS*) Journal, n. 10, Special Issue Media, Internet and Social Movements in the context of asymmetries, p. 11-34, 2016. . Mais conectados, mais comuns? Recursos digitais nas experiências midiáticas apresentadas no $8^{\circ}$ Mutirão Brasileiro de Comunicação. In PERUZZO, C. M.; OTRE, M. A. Comunicação Popular, Comunitária e Alternativa no Brasil. Sinais de resistência e de construção da cidadania. São Bernardo do Campo: UMESP, 2015. p. 222-245. 
. Which media for improving democracy? 2014 ECPR Graduate Student Conference. Innsbruck, Áustria, 2014.

TACCHI, J. Being meaningfully mobile: mobile phones and development. In SERVAES, J. Technological Determinism and Social Change. Lanham, MD: Lexington Books, 2017. p. $105-124$. 